\title{
ANÁLISE DAS PROPRIEDADES FÍSICAS DO CONCRETO OBTIDO COM USO DE POLIETILENO TEREFTALATO (PET)
}

\section{ANALYSIS OF PHYSICAL PROPERTIES OF CONCRETE OBTAINED FROM THE USE OF POLYETHYLENE TEREPHTHALATE (PET)}

Cassio Fabian S. Campos, Daniele AraujoAltran, Guilherme Noboru Sassaki Fidelis, Leonardo Borges de Oliveira

Universidade do Oeste Paulista - UNOESTE. Faculdade de Engenharia, Presidente Prudente, SP. e-mail: noborumg3@gmail.com

RESUMO - No Brasil a indústria produtora de garrafas PET (Polietileno Tereftalato) é recente, e cresce de maneira exorbitante, aumentando os problemas causados pelo descarte inadequado desse material no meio ambiente. Por outro lado, a construção civil cresce a cada ano retirando do meio ambiente a areia para a fabricação de concreto. Este estudo teve por objetivo analisar a substituição parcial da areia pelo PET triturado na produção de concreto, visando à redução da extração de areia do meio ambiente e diminuição do resíduo sólido e desenvolver um novo material para a construção civil. Para tanto, foram produzidos corpos de prova cilíndricos, substituindo parcialmente a areia e verificada sua resistência segundo as normas NBR 5738 (ABNT, 2003) e NBR 5739 (ABNT, 1994). Constatou-se que a alternativa ecológica analisada é de viável execução no caso de construção de mobiliários urbanos simples, como por exemplo: calçadas e sarjetas cuja resistência exigida é na faixa de $10 \mathrm{MPa}$ a 15MPa.

Palavras-chave: PET; concreto; agregado reciclado.

ABSTRACT - In Brazil the industry that produces PET (Polyethylene Terephthalate) bottles is a recent and growing exorbitantly increasing problems caused by inappropriate disposal of this material on the environment. On the other hand, the civil construction increases every year by removing the sand from the environment to manufacture of concrete. This study aimed to analyze the partial replacement of sand by PET crushed in concrete production, aiming to reduce the extraction of sand from the environment and reduction of solid waste and develop a new material for construction. For this, sample cylindrical were produced, partially replacing the sand and tested its resistance according to NBR 5738 (ABNT, 2003) and NBR 5739 (ABNT, 1994). Was found that examined the ecological alternative is feasible execution in case of construction of simple street furniture, such as

Recebido em: 19/08/2014 Revisado em: 29/08/2014 Aprovado em: 08/09/2014 example: sidewalks and gutters whose resistance required is in the range of $10 \mathrm{MPa}$ to $15 \mathrm{MPa}$.

Keywords: PET; concrete; recycled aggregate. 


\section{INTRODUÇÃO}

No Brasil, a Associação Brasileira da Indústria do PET (2012) (ABIPET) é a associação responsável pela produção do PET (Polietileno Tereftalato) e também pela destinação do descarte ideal, de maneira que este cause mínimo ou nenhum impacto negativo ao meio ambiente. Diante do crescimento constante da utilização desse plástico, uma consistente gestão de resíduo do material que possibilite reciclagem é indispensável, uma vez que a produção excessiva e o depósito irregular contribuem para a degradação do meio ambiente.

Segundo Canellas (2005), a indústria da construção civil, como uma das maiores geradoras de resíduos, podendo chegar a 3000 kg/hab.ano, não pode se eximir desta responsabilidade de gestão de resíduo e material. A construção civil consome grandes quantidades de recursos naturais, um grande número de estudos para substituição de bens naturais não renováveis tem sido realizado nesse setor, aliando materiais convencionais com resíduos industriais e urbanos.

Um dos materiais que vem sendo utilizado nestas pesquisas são as embalagens pós-consumo de PET, resíduos que estão atingindo percentuais cada vez maiores na composição do lixo urbano, com presença crescente no meio ambiente, segundo a Associação Brasileira da Indústria do PET (2012). Para Pareja et al. (2009) a reciclagem de resíduos sólidos, principalmente, os plásticos é uma das opções encontradas atualmente para a redução da quantidade destes resíduos descartados indevidamente no ambiente.

Piva e Wiebeck (2004) afirma que segundo estimativa da ABREMPLAST (Associação Brasileira de Recicladores de Materiais Plásticos) atualmente são recicladas cerca de 13 mil toneladas de plásticos por mês, em toda Grande São Paulo. Os plásticos pós-consumo são responsáveis por $49 \%$ do total reciclado pelos 180 recicladores da Grande São Paulo que reciclam $16 \%$ do total produzido. No Rio de Janeiro, são reciclados $18,6 \%$ do total. As resinas plásticas em 2002 foram destinadas para: embalagens $(39,73 \%)$, construção civil $(13,67 \%), \quad$ descartáveis $\quad(11,55 \%)$, componentes técnicos (8,04\%), agrícola (7,67\%), utilidades domésticas (4,72\%), outros $(14,62 \%)$ e cerca de $17,5 \%$ dos plásticos rígidos e filme consumidos no Brasil retornam à produção como matéria-prima, o que equivale a cerca de 200 mil toneladas por ano. Deste total, $60 \%$ provêm de resíduos industriais e $40 \%$ do lixo urbano.

Leve, resistente e prático, o plástico rígido é o material que compõe cerca de $77 \%$ das embalagens plásticas no Brasil, totalizando 3,9 milhões de toneladas de plástico por ano. Dessas, aproximadamente $40 \%$ têm com vida útil curta. 0 plástico pode 
ser reprocessado, gerando novos artefatos plásticos e energia (CEMPRE, 2009).

Justifica-se esta pesquisa pelo fato do alto índice de descarte de PET na natureza, quer seja em lixões ou não, sendo então oferecida uma opção de reaproveitamento do material e contribuição para a diminuição de resíduo sólido, que ao ser retirado de lixões ou locais de descartes inadequados, contribuirá para a preservação do meio ambiente.

Esta pesquisa visa utilizar o PET usado em garrafas de refrigerantes, para substituir parcialmente areia natural, objetivando a produção de concreto de $20 \mathrm{MPa}$ para uso na construção civil. Para tanto, porcentagens de PET e areia foram combinados e testados, os ensaios foram executados no Laboratório de Materiais de Construção do Campus II da UNOESTE - Universidade do Oeste Paulista, conforme normas específicas para a validação do concreto. Foram analisadas principalmente as características de trabalhabilidade, resistência à compressão, além do índice de vazios, teor de absorção e massa específica.

\section{METODOLOGIA}

Inicialmente foram produzidos corpos de prova de concreto comum (segundo NBR 5738), sem adição de PET com o intuito de cumprir o papel de concreto piloto, para que se conheçam as propriedades que um concreto normal apresenta. Os resultados dos pilotos serão utilizados como padrão para se analisar os concretos produzidos com PET. Os corpos de prova foram fabricados com cimento Portland CPII-E 32, areia, brita 1 e, posteriormente, agregado miúdo de PET. O traço piloto adotado foi de $20 \mathrm{MPa}$ e sua dosagem de Silva (1975).

Após fabricação e moldagem dos corpos de prova, ensaios foram realizados para avaliar o concreto com idades de 7, 14, 21 e 28 dias, as análises tiveram como objetivo trazer resultados, enfaticamente, de duas características: resistência à compressão e trabalhabilidade do concreto seguindo as normas NBR 5739 (ABNT, 1994) e NBR NM 67:1998 (ABNT, 1998), respectivamente - sendo que, esta última deu-se através do slump test. Por último, quando os corpos de prova atingiram a idade de 28 dias foi realizado o ensaio de acordo com a norma NBR 9778 (ABNT, 2005) para determinação do índice de vazios, teor de absorção e massa específica.Com o intuito de estudar as alterações que ocorrem no concreto com uso de agregado reciclado, a substituição de areia por PET foi feita gradativamente, na proporção de 5\%, 10\%, $15 \%, 20 \%$ e $25 \%$.

Para esse experimento foram utilizados agregados adquiridos em lojas de materiais de construção da região de Presidente Prudente e o PET reciclado foi 
obtido através da empresa "HPF PET Flakes", situada em Ribeirão Preto - SP, que realiza a reciclagem de materiais de plástico e comercializa o PET já como um agregado miúdo, pois este apresenta a granulometria de areia média (HELENE; TERZIAN, 1992).

A areia utilizada é quartzosa, classificada como areia média, apresentando módulo de finura 3,42 enquanto que a brita de basalto para fabricação dos corpos de prova, granulometricamente classificada com brita 1, obtida em lojas de construção da cidade Presidente Prudente- SP, possui módulo de finura de 6,6 e diâmetro máximo de $19,1 \mathrm{~mm}$.

Tabela 1. Granulometria do PET triturado.

\begin{tabular}{c|c|c|c}
\hline $\begin{array}{c}\text { Especificação das } \\
\text { peneiras } \\
\text { (NBR 7217/87) }\end{array}$ & $\begin{array}{c}\text { Massa Retida } \\
(\mathrm{g})\end{array}$ & $\begin{array}{c}\text { Porcentagem Retida } \\
\text { Acumulada }\end{array}$ & $\begin{array}{c}\text { Porcentagem } \\
\text { Passante }\end{array}$ \\
\hline $4,76 \mathrm{~mm}$ & 19,14 & 1,91 & 98,08 \\
\hline $2,38 \mathrm{~mm}$ & 37,42 & 5,66 & 94,34 \\
\hline $1,49 \mathrm{~mm}$ & 315,89 & 37,26 & 62,74 \\
\hline $0,59 \mathrm{~mm}$ & 397,10 & 76,99 & 23,01 \\
\hline $0,297 \mathrm{~mm}$ & 120,19 & 89,02 & 10,98 \\
\hline $0,149 \mathrm{~mm}$ & 64,93 & 95,51 & 4,49 \\
\hline $0,074 \mathrm{~mm}$ & 25,31 & 98,04 & 1,96 \\
\hline$<0,074 \mathrm{~mm}$ & 19,54 & 100,00 & 0,00 \\
\hline
\end{tabular}

Fonte: Os Autores.

Inicialmente estabeleceu-se o traço piloto de resistência de 20MPa, posteriormente, analisou-se dois fatores que foram intrínsecos no momento do cálculo da quantidade ideal (em massa) da substituição de agregado miúdo, sendo estes a massa específica e a umidade dos agregados
Como areia e PET possuem massa específica diferentes é importante que correções sejam feitas nas dosagens para se obter a mesma quantidade de concreto. Para tanto, utilizou-se os procedimentos da NBR NM 52:2009 (ABNT, 2009).

\section{RESULTADOS E DISCUSSÃO}

As garrafas PET trituradas foram obtidas pela empresa de Ribeirão Preto - SP, o agregado miúdo de PET utilizado tem granulometria semelhante da areia sendo classificada como areia média apresentou módulo de finura 3,3, conforme mostra os resultados de testes granulométricos, expostos na Tabela 1. 
O traço utilizado para o concreto piloto (Tabela 2) serviu de base para os demais, sendo feita alteração apenas na proporção de PET e areia.

Tabela 2. Traço do concreto piloto.

Fonte: Silva (1975).

\begin{tabular}{c|c}
\hline Materiais & $\begin{array}{c}\text { Composição unitária em massa } \\
\text { por } \mathrm{m}^{3}\end{array}$ \\
\hline Brita 1 & 1038 \\
\hline Areia (seca) & 791 \\
\hline Cimento & 302 \\
\hline Água & 211 \\
\hline Fator a/c & 0,70 \\
\hline
\end{tabular}

Os traços para ensaios foram em proporções de substituição de $5 \%$ em $5 \%$, até se chegar a $25 \%$ de substituição da areia pelo
PET. Sendo assim, os traços com PET de 5\%, $10 \%, 15 \%, 20 \%$ e $25 \%$ foram calculados e executados, conforme Tabela 3.

Tabela 3. Traços de concreto com PET, composição para um metro cúbico.

Fonte: Os autores.

\begin{tabular}{c|c|c|c|c|c} 
Materiais & $\begin{array}{c}5 \% \text { PET } \\
\left(\mathrm{kg} / \mathrm{m}^{3}\right)\end{array}$ & $\begin{array}{c}10 \% \text { PET } \\
\left(\mathrm{kg} / \mathrm{m}^{3}\right)\end{array}$ & $\begin{array}{c}15 \% \text { PET } \\
\left(\mathrm{kg} / \mathrm{m}^{3}\right)\end{array}$ & $\begin{array}{c}20 \% \text { PET } \\
\left(\mathrm{kg} / \mathrm{m}^{3}\right)\end{array}$ & $\begin{array}{c}25 \% \text { PET } \\
\left(\mathrm{kg} / \mathrm{m}^{3}\right)\end{array}$ \\
\hline Brita 1 & 1038 & 1038 & 1038 & 1038 & 1038 \\
\hline $\begin{array}{c}\text { Areia } \\
\text { (seca) }\end{array}$ & 751,45 & 711,9 & 672,35 & 632,8 & 593,25 \\
\hline PET & 18,89 & 37,79 & 56,68 & 75,57 & 94,47 \\
\hline Cimento & 302 & 302 & 302 & 302 & 302 \\
\hline Água & 211 & 211 & 211 & 211 & 211 \\
\hline Fator a/c & 0,70 & 0,70 & 0,70 & 0,70 & 0,70 \\
\hline
\end{tabular}

Um dos fatores relevantes ao analisar o concreto produzido é a trabalhabilidade, que sofre alterações principalmente de acordo com o fator água/cimento e agregados utilizados. No ensaio realizado de acordo com a norma NM 67:1998 (ABNT,
1998), o concreto com teores de substituição de $15 \%, 20 \%$ e $25 \%$ de PET mostrou resultados de slump test com mau desempenho sendo portanto de difícil trabalhabilidade (Tabela 4).

Tabela 4. Resultados do Slump Test.

\begin{tabular}{c|c}
\cline { 2 - 2 } & NM 67:1998 \\
\hline Traço & Abatimento do Cone $(\mathbf{c m})$ \\
\hline Piloto & 3,5 \\
\hline $5 \%$ de PET & 2,0 \\
\hline $10 \%$ de PET & 1,5 \\
\hline $15 \%$ de PET & 0,0 \\
\hline $20 \%$ de PET & 0,0 \\
\hline $25 \%$ de PET & 0,0 \\
\hline
\end{tabular}

Fonte: Os autores. 
Com relação aos testes de compressão, cada traço foi realizado 6 vezes, então foram feitas s médias dos resultados, que são apresentadas na Tabela 5, em MPa e Gráfico 1.

Tabela 5. Média das Resistências a Compressão em MPa.

Fonte: Os autores.

\begin{tabular}{c|c|c|c|c}
\cline { 2 - 5 } & \multicolumn{4}{c}{ Idade do Concreto } \\
\hline Traço & 7 Dias & 14 Dias & 21 Dias & 28 Dias \\
\hline Piloto & 18,61 & 25,58 & 23,77 & 29,22 \\
\hline 5\% de PET & 8,64 & 11,12 & 11,82 & 12,66 \\
\hline 10\% de PET & 9,78 & 10,99 & 12,16 & 13,76 \\
\hline 15\% de PET & 11,58 & 15,09 & 14,49 & 16,61 \\
\hline 20\% de PET & 8,98 & 10,64 & 10,02 & 11,90 \\
\hline 25\% de PET & 3,80 & 5,21 & 5,39 & 6,04 \\
\hline
\end{tabular}

Gráfico 1. Resistência à Compressão para todos os traços e idades estudados.

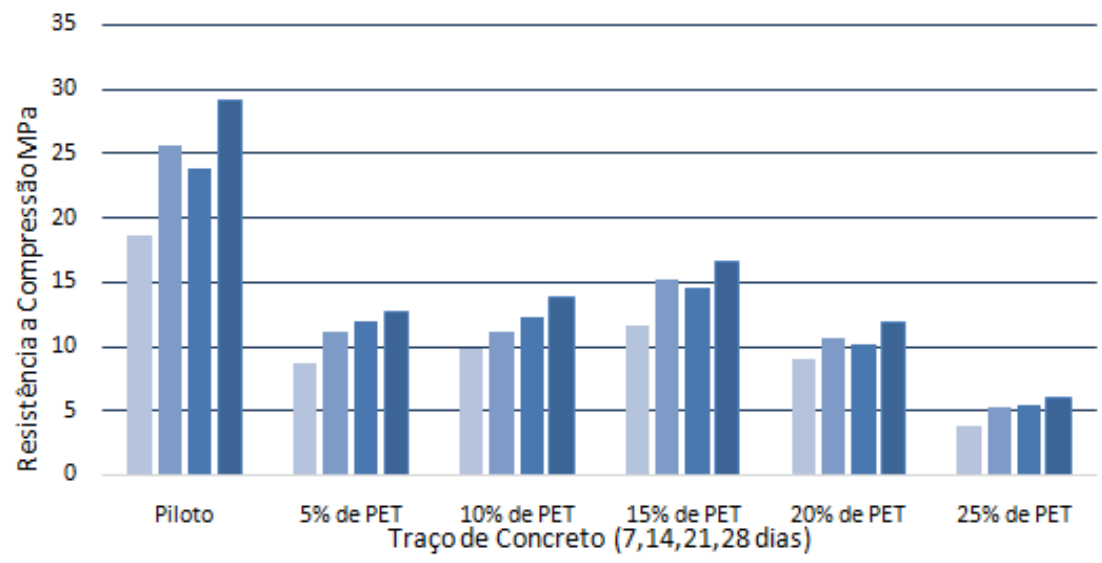

Fonte: Os Autores.

Verifica-se na Tabela 5 que o traço do concreto piloto teve ótimo desempenho e ultrapassou o valor de $20 \mathrm{MPa}$, chegando a $29,22 \mathrm{MPa}$ ao final dos 28 dias. Os traços de concreto com PET não atingiram o mesmo nível, sendo que o traço de $15 \%$ de PET apresentou resistência de compressão de $16,61 \mathrm{Mpa}$ aos 28 dias de idade, sendo traço de concreto mais resistente obtido, mas ainda assim, abaixo do desejado 20MPa.

O Gráfico 1, mostra os valores máximos de resistência a compressão alcançados e que embora os $20 \mathrm{MPa}$ não tenha sido atingido no experimento 16,61MPa constitui um nível de resistência utilizado em diversos traços de concreto em obras, sem fins de sustentação estrutural.

Com relação aos resultados para o ensaio de determinação do teor de absorção, índice de vazios e massa específica do concreto, executado conforme a norma NBR 9778 (ABNT, 2005) chegou-se aos seguintes resultados da Tabela 6. 
Tabela 6. Teor de Absorção, Índice de vazios e Massa Específica.

Fonte: Os Autores.

\begin{tabular}{c|c|c|c}
\hline Traço & $\begin{array}{c}\text { Teor de } \\
\text { absorção } \\
\mathbf{( \% )}\end{array}$ & $\begin{array}{c}\text { Índice de } \\
\text { vazios } \\
\mathbf{( \% )}\end{array}$ & $\begin{array}{c}\text { Massa } \\
\text { específica } \\
\left(\mathbf{g} / \mathbf{c m}^{\mathbf{3}} \mathbf{)}\right.\end{array}$ \\
\hline Piloto & 4,52 & 10,66 & 2,36 \\
\hline $5 \%$ de PET & 5,92 & 13,51 & 2,28 \\
\hline $\begin{array}{c}10 \% \text { de } \\
\text { PET }\end{array}$ & 5,94 & 13,01 & 2,19 \\
\hline $\begin{array}{c}15 \% \text { de } \\
\text { PET }\end{array}$ & 6,56 & 14,19 & 2,16 \\
\hline $\begin{array}{c}20 \% \text { de } \\
\text { PET }\end{array}$ & 7,23 & 15,37 & 2,12 \\
\hline $\begin{array}{c}25 \% \text { de } \\
\text { PET }\end{array}$ & 11,88 & 23,71 & 2,08 \\
\hline
\end{tabular}

Nesse ensaio, o índice de vazios representa o valor total de poros no concreto e o teor de absorção diz respeito apenas aos poros permeáveis, que fazem conexão entre a superfície e o núcleo da estrutura.

Nota-se nestes testes que o aumento na proporção de PET de concreto produziu um aumento tanto no teor de absorção quanto no índice de vazios (Gráfico 2). Essa relação proporcional tem como causa o mau adensamento do concreto com PET, já constatado no slump test, uma vez que dessa maneira o agregado reciclado prejudica a propriedade aglomerante do cimento, deixando uma maior quantidade de vazios na estrutura do concreto.

Gráfico 2. Teor de absorção e índice de vazios.

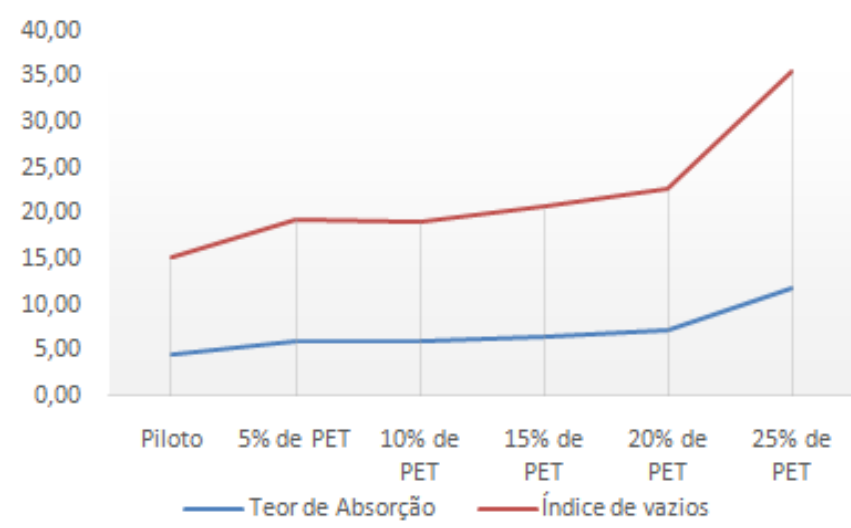

Fonte: Os autores.

Com relação à massa específica do concreto constatou-se que a utilização do agregado de PET reduz a massa específica e assim obtém-se um concreto mais leve que o convencional (Gráfico 3). 
Gráfico 3. Massa específica do concreto.

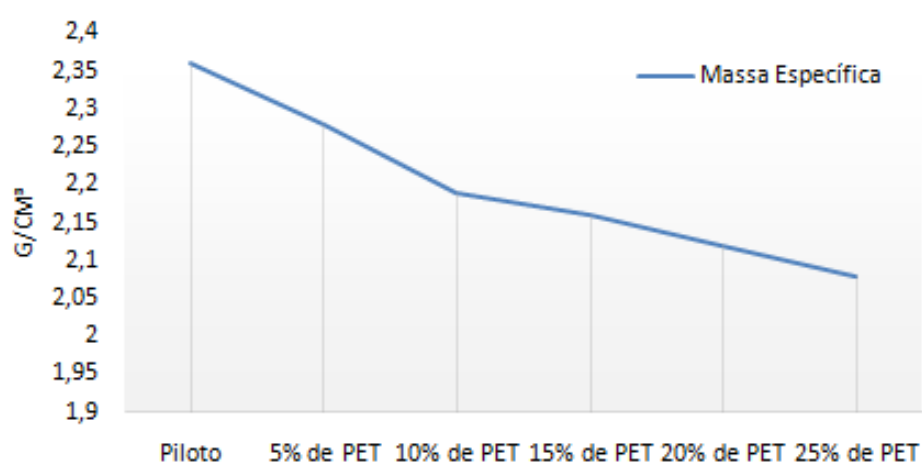

Fonte: Os autores.

\section{CONCLUSÃO}

O estudo realizado se baseou em traços já existentes do concreto tradicional, substituindo apenas o agregado miúdo, resultando em uma diminuição de resistência e trabalhabilidade, que são propriedades fundamentais quando se analisa a utilização da mistura. $O$ estudo conclui que a utilização de PET reciclado como agregado miúdo é uma alternativa válida, visando reduzir os impactos ao meio ambiente da ampla utilização de areia e o descarte de resíduos plásticos, porém o concreto produzido com PET não apresenta um nível seguro para se trabalhar com fins estruturais, constatação com base na NBR 8953, que determina um grupo de concreto para cada nível de resistência, sendo os traços com PET classificados como concreto sem fins estruturais.

A utilização do concreto com PET é limitada se comparada com o traço tradicional, a alternativa ecológica em questão é de viável execução no caso de construção de mobiliários urbanos simples, como exemplo pode-se citar calçadas, sarjetas, bancos ou degraus, onde a resistência exigida fica na faixa de $10 \mathrm{MPa}$ a 15MPa. A redução no volume de areia e um fim adequado a esse resíduo plástico, a longo prazo tem um valor inestimável ao meio ambiente. Entretanto, o concreto com PET apresenta baixa trabalhabilidade, impossibilitando sua execução em pequenos formatos.

Os traços utilizando $20 \%$ e $25 \%$ apresentaram alto valor no índice de vazios e teor de absorção devido ao mau adensamento dos componentes do concreto, reduzindo a resistência à compressão, apresentando valores impraticáveis. As substituições de $10 \%$ e $15 \%$ apresentaram os melhores resultados, com valores razoáveis de resistência à compressão, assim como teor de absorção e índice de vazios, tornando possível a utilização desses traços como opção ecológica em artefatos simples, trabalhando com resistência entre $10 \mathrm{MPa}$ e 15MPa. 


\section{REFERÊNCIAS}

ASSOCIAÇÃO BRASILEIRA DA INDÚSTRIA DO PET - ABIPET. 8 Censo da Reciclagem de PET no Brasil. 2011. Disponível em: <www.abipet.org.br>. Acesso: 28 de junho. 2012.

ASSOCIAÇÃO BRASILEIRA DE NORMAS TÉCNICAS - ABNT. NBR 5738 - concreto: procedimento para moldagem e cura de corpos de prova, para realizar os ensaios de resistência à compressão. Rio de Janeiro, 2003.

ASSOCIAÇÃO BRASILEIRA DE NORMAS TÉCNICAS - ABNT. NBR 5739 - concreto: ensaio de compressão de corpos-de-prova cilíndricos. Rio de Janeiro, 1994.

ASSOCIAÇÃO BRASILEIRA DE NORMAS TÉCNICAS - ABNT. NBR 9778 - argamassa e concreto endurecido. Determinação da absorção de água, índice de vazios e massa específica. Rio de Janeiro, 2005.

ASSOCIAÇÃO BRASILEIRA DE NORMAS TÉCNICAS - ABNT. NBR NM 52:2009 agregado miúdo. Determinação de massa específica e massa específica aparente. Rio de Janeiro, 2009.

ASSOCIAÇÃO BRASILEIRA DE NORMAS TÉCNICAS - ABNT. NBR NM 67:1998 concreto - Determinação da consistência pelo abatimento do tronco de cone. Rio de Janeiro, 1998.

CANELLAS, S.S. Reciclagem de PET, visando substituição de agregado miúdo em argamassa. 2005. Dissertação (Mestrado) Departamento de Ciência dos Materiais e Metalurgia, Pontifícia Universidade Católica do Rio de Janeiro, Rio de Janeiro - RJ. http://dx.doi.org/10.17771/pucrio.acad.7374

CEMPRE. Plástico rígido. 2009. Disponível: <http://www.cempre.org.br/ft_plastico.php> . Acesso: 17 abr. 2012.
HELENE, P.; TERZIAN, P. Manual de dosagem e controle do concreto. São Paulo: PINI, 1992. 349p.

PAREJA, J.A.M. et al. Utilização do polietileno de alta densidade como agregado em substituição a areia na produção de concreto. In: SIMPÓSIO DE PÓS GRADUAÇÃO EM ENGENHARIA URBANA. Maringá, PR, 2009.

PIVA, A.M.; WIEBECK, H. Reciclagem do plástico. São Paulo: Art Líber, 2004.

SILVA, G.R. Manual de traços de concreto. São Paulo: Nobel, 1975. 